\title{
Publisher Correction: Beliefs about minority groups
}

Jenn Richler

Correction to: Nature Climate Change https://doi.org/10.1038/s41558-018-0365-9, published online 29 November 2018.

In the version of this Research Highlight originally published, Adam Pearson's institute was incorrectly given as 'Ponoma College'; it should have read 'Pomona College'. This has now been corrected.

Published online: 10 January 2019

https://doi.org/10.1038/s41558-019-0403-2

\section{Publisher Correction: Boreal forest biomass accumulation is not increased by two decades of soil warming}

Hyungwoo Lim (D), Ram Oren (D), Torgny Näsholm, Monika Strömgren, Tomas Lundmark, Harald Grip and Sune Linder

Correction to: Nature Climate Change https://doi.org/10.1038/s41558-018-0373-9, published online 17 December 2018.

In the version of the Supplementary Information file originally published with this Letter, ref. $42-$ Andersson, P., Berggren, D. \& Nilsson, I. Indices for nitrogen status and nitrate leaching from Norway spruce (Picea abies (L.) Karst.) stands in Sweden. For. Ecol. Manag. 157, 39-53 (2002) - should have appeared as a footnote to Supplementary Table 2; this has now been added. 